\title{
A SIMBIOSE ENTRE DIREITO E NATUREZA A PARTIR DO ENUNCIADO PERFORMATIVO
}

\author{
THE SYMBIOSIS BETWEEN LAW AND NATURE FROM THE \\ PERFORMATIVE SPEECH
}

\author{
Lucas Bertolucci ${ }^{\mathrm{I}}$ \\ Marcos César Botelho ${ }^{\text {II }}$
}

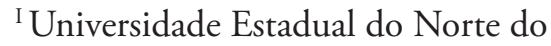

Paraná, Jacarezinho, PR, Brasil. Mestre em Ciência Jurídica. E-mail: lucas. bertolucci@gmail.com
\end{abstract}

${ }^{\text {II }}$ Universidade Estadual do Norte do Paraná, Jacarezinho, PR, Brasil. Doutor em Direito. E-mail: mc_botelho@yahoo. com.br

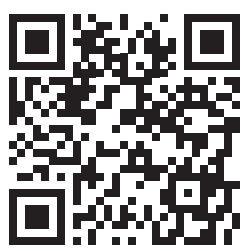

DOI: http://dx.doi.org/10.31512/rdj.v21i40.400

Recebido em: 06.12.2019

Aceito em: 20.10.2020
Resumo: Quando se fala em "natureza", parece haver uma certa indeterminação entre o mundo físico e a ideia que se tem dele. Afinal, seria a natureza enquanto mundo físico anterior à ideia de natureza? Ou, pelo contrário, é a própria ideia que delimita o que é natureza? Estes questionamentos foram desenvolvidos neste trabalho, por meio de uma metodologia dedutiva e da leitura bibliográfica. Num primeiro momento, foram trazidos alguns exemplos de metafísicas modernas sobre a natureza, com o fim de demonstrar a presença, nelas, do princípio da causalidade e de como ele se relaciona com o direito. Em seguida, expôs-se as teorias de David Hume e de Hans Kelsen, que tentam salvaguardar a separação entre pensamento e mundo, e a náo-anterioridade deste. Por fim, tentou-se mostrar, por meio de um breve excurso histórico, a criação da ideia de mundo nos filósofos pré-socráticos da Grécia Antiga, em sua busca da delimitação da natureza; evidenciou-se, além disso, a partir da genealogia empreendida por Hans Kelsen, a influência da regra da retribuição, também conhecida por lei de taliáo, nos sistemas filosóficos.

Palavras-chave: Direito. Natureza. Performativo.

Abstract: When someone speaks of "nature", it seems to be a kind of indetermination between the physical world and one's idea about it. Would nature, as physical world, precede the idea of nature? Or, otherwise, is the very idea of nature itself that delimits what is nature? These questions were developed in the present work, by means of a deductive methodology and bibliographical reading. Firstly, some examples of modern metaphysics about nature were brought to show the presence, in them, of the principle of causality and its relation with Law. Then, David Hume's and Hans Kelsen's theories, which try to preserve the dissociation between thinking and world, and the non-anteriority of the latter, were exposed. Finally, the work tried to show, through a brief historical journey, the creation of the idea of world by the pre-Socrates philosophers of the Old Greece in their quest of nature delimitation. It was made evident, besides that, from the genealogy by Hans Kelsen, the influence of the retribution rule, also known as the talion law, in the philosophical systems.

Keywords: Law. Nature. Performative. 


\section{CONSIDERAÇÓESS INICIAIS}

A linha que separa as ciências humanas das ciências da natureza é não apenas tênue, mas extremamente difusa. Pois, em que medida o objeto das ciências humanas não está contido nas ciências da natureza, e em que medida seriam estas menos humanas que as demais? Todo o debate acerca da dualidade natureza e espírito leva a inúmeros questionamentos, e à impossibilidade de se formular uma resposta simples. Por esta razão, o presente artigo teve como objetivo refutar ou ao menos investigar as condiçóes para um futuro questionamento - o possível caráter causal da natureza e o possível caráter imputável do direito.

No primeiro capítulo, após uma breve exposição da diferença, em Kelsen, entre o princípio da imputação e o princípio da causalidade, investigo algumas ocorrências, nas metafísicas científicas modernas, dos princípios da causalidade e da imputação, concomitantemente. Tanto a metafísica cristá religiosa, quanto as metafísicas empiricistas e a metafísica de Descartes, tentaram criar uma ciência da natureza que fosse articulada causalmente, em relações de causa e efeito e que, ao mesmo tempo, tivessem uma causa final. Esses dois aspectos mostram uma mistura, respectivamente, do princípio da causalidade e do princípio da imputação.

No segundo capítulo, duas teorizaçóes - a de David Hume e a de Hans Kelsen - são expostas, como formulaçóes que pretendem separar os princípios em união: Hume tenta afastar a imputação das ciências naturais, Kelsen tenta afastar a causalidade da ciência jurídica. A seguir essa suposta tentativa de separação é questionada e investigada a partir de certas teorizaçóes filosóficas.

No terceiro capítulo, faço uma retomada histórica do momento em que ambos princípios se relacionam pela primeira vez. $\mathrm{Na}$ verdade, os dois princípios surgem da chamada "regra da retribuição", a regra primitiva que determina que todo mal (ilícito) deve ser respondido com um mal (pena) igual ou equivalente. Na constituição da ciência, na Grécia Antiga, os gregos fizeram uso, para a criação de seus esquemas científicos, das categorias normativas e sociais de que dispunham, e a regra da retribuição é a que rege todo o agrupamento social. Portanto a regra da retribuição formalizou toda a ciência, desde a antiguidade até a modernidade.

Buscar uma relação originária entre o direito e a natureza possibilita o esclarecimento de alguns pontos obscuros acerca da capacidade de representação das metafísicas, bem como do poder criativo do jurídico. Não se quis, porém, dar uma resposta final para esses problemas, aparentemente inexplicáveis. O que ambicionamos é, tão somente, contribuir de alguma forma para o debate. 


\section{HANS KELSEN E A DIVISÃO ENTRE CAUSALIDADE NATURAL E IMPUTAÇÃO JURÍDICA}

As várias tentativas de explicar a totalidade dos fenômenos do mundo tenderam a acabar, em toda a história da humanidade, com a colocação de uma "causa final" que explicasse o processo todo. Nota-se isso já nas formulaçôes dos mais antigos filósofos pré-socráticos, que buscavam interpretar a natureza em sua suposta completude. Tales determinou que a água fosse a última causa, enquanto Anaxímenes, o ar. Anaximandro, por sua vez, e para não recair na causa final como algo mundano e visível, afirmou que a causa final é uma substância infinita, chama,

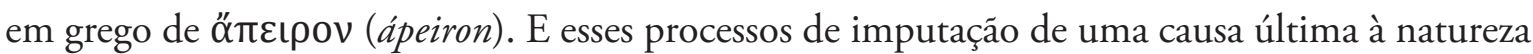
se deu em todo o decorrer histórico.

$\mathrm{Na}$ metafísica divina do final da Idade Média e do início da modernidade, Deus é tido como a substância que determina como acontecem todas as relaçôes fáticas do mundo. Logo, os hábitos também entram na trama divina, de modo que todos os acontecimentos e relaçóes humanas se justificam a partir do conto da Divina Providência. Se tudo se dá por uma razão, se tudo acontece por uma causa, essa causa é Deus. O cristianismo, enquanto metafísica específica da cristandade, sustenta a ideia de que o retorno do Messias, a parúsia, se dará a qualquer momento, que este momento já é predestinado a ocorrer, e que, em sua ocasião, a Igreja Divina descerá até a Igreja Mundana, e o tempo eterno terá lugar. Pode-se afirmar, pois, que, segundo essa lógica, toda imputação se submete à causalidade, de modo que a causalidade divina predetermina, em última instância, toda imputação.

Com o renascimento, a supremacia da religiáo católica na Europa, apesar de náo contestada no âmbito estritamente religioso, não dominava mais toda a cultura. A ciência passou a ocupar o lugar hegemônico que a religião possuía na cultura europeia, com a ascensão do experimentalismo por meio de personagens como Leonardo da Vinci. A prática empirista tinha como método a experiência prática, e como objetivo descobrir o mundo em sua completude, a partir da indução. É a experiência, no ideário experimentalista, que opera como ponte entre o homem e a natureza. No entanto, apesar de se contrapor à ideia providencial cristã, o cientificismo emergente não é vazio de metafísica, não se sustenta tão somente pela indução. Existe uma metafísica que funciona como base dessa lógica científica, e que é a metafísica da razão, a secularização de Deus na racionalidade definitiva do universo, e a crença nessa racionalidade (DAWSON, 2012, p. 219).

Isso significa que surge, portanto, uma metafísica mecanicista, a criação da ideia de uma res extensa necessária, ou seja, de uma absoluta lógica imanente do universo. Toda a natureza é, então, interpretada como um todo mecanicamente fechado, e, ao menos virtualmente, passível de ser completamente descoberto. Contudo, a crença na racionalidade matemática da natureza implica, se levada ao extremo, na inscrição do homem nessa lógica espaço-temporal pré definida pela natureza, e, consequentemente, no esvaziamento da própria subjetividade frente a absoluta objetividade. 
O homem não só havia perdido seu lugar central no universo como a ligação entre a realidade mais alta do espírito e a realidade mais baixa da matéria; ele corria o perigo de ser empurrado para fora da ordem inteligível. Pois se o universo é concebido como uma ordem mecânica fechada, governada por leis matemáticas, não existe mais espaço nele para os valores morais e espirituais que até entáo tinham sido considerados como a realidade suprema. Daí pareceria seguir que o mundo da consciência humana era subjetivo e irreal e que o próprio homem nada mais era que subproduto da vasta ordem mecânica que a nova ciência havia revelado. [...] A realidade da ordem moral e espiritual era admitida não apenas pela vasta maioria dos homens, mas também pelos líderes do novo pensamento. Porém, ele não podia mais ser integrado no sistema do universo material em uma única ordem de realidade. Consequentemente, a tentativa mais poderosa do novo pensamento de produzir uma síntese filosófica - o sistema cartesiano - resultou em um dualismo filosófico estrito da mente e do espírito, "res extensa and res cogitans". (DAWSON, 2012, p. 220-221)

Portanto, a filosofia cartesiana busca resolver o problema do sujeito frente a um mecanismo absoluto e universal, isto é, sustenta a existência de um ser individual, apesar da necessidade que ordena os corpos. René Descartes, filósofo e matemático francês, nascido ao final do século XVI, em suas Meditaçóes da filosofia primeira (1641), traz sua ideia de causalidade a partir de uma metafísica calcada em um Deus onipotente e onisciente. Descartes não abre mão do Deus cristão, que tudo sabe e que tudo cria, e dentre as coisas por Ele criadas está o ser pensante, o "eu" cartesiano. Confrontado ao mundo da sua volta, o "eu" nada sabe sobre a veracidade daquilo vê ou sente. Como seria possível ao "eu" determinar de uma vez por todas que aquilo que vive em tal momento, ou em toda a sua vida, é ou não é a realidade? Também os sonhos trazem pensamentos que iludem, colocam uma certa narrativa como a realidade. "E, quando penso mais atentamente, vejo do modo mais manifesto que a vigília nunca pode ser distinguida do sono por indícios certos, fico estupefato e esse mesmo estupor quase me confirma na opinião de que estou dormindo" (DESCARTES, 2004, p. 25).

E sendo a determinação entre sonho e realidade, em última instância, impossível, o que resta ao indivíduo? O sujeito cartesiano é a coisa pensante; apesar de nada se saber sobre o que se sente ou sobre o que se vê, o "eu" é o que há de verdadeiro, pois sabe que sente, ou sabe que vê. E por mais distorcida que seja a realidade, e por mais que o que o sujeito percebe nunca seja aquilo que lhe é "enviado", o sujeito cartesiano sabe ao menos que pensa. O ser pensante é, pois, absolutamente separado da realidade corpórea, e inclusive de seu próprio corpo fisiológico; ele é puro pensamento. Do pensamento decorre a faculdade de juízo, e é a partir desta faculdade que é possível julgar que se vê, se sente ou se imagina algo. A partir desta faculdade, não se percebe, pois, as coisas extensas do mundo, mas sim, e unicamente, o próprio pensar. $\mathrm{O}$ julgamento a respeito de algo pode ser verdadeiro ou falso, mas a faculdade de julgar é inegavelmente verdadeira (DESCARTES, 2004, p. 59).

Toda ideia é, nesse sentido, proveniente da faculdade de julgar e, portanto, proveniente do pensamento, e não passa de um modo de pensar. As ideias referentes às percepçóes - chamadas por Descartes de "adventícias" - recebem do pensamento uma realidade objetiva, isto é, são tidas 
pelo eu pensante como a própria realidade, misticamente confundidas com o mundo corpóreo. No entanto, permanece a dúvida a respeito de a realidade objetiva assumida por determinada ideia ser especificamente de uma certa maneira, e não de outra; ao que o filósofo francês afirma haver alguma causa da qual a ideia recebe uma realidade formal, ou seja, uma causa responsável por dar à realidade objetiva (percebida) a forma que esta possui. A esta causa, Descartes dá o nome de "substância infinita", ou Deus.

É a substância infinita, Deus, que tudo cria e que todas as relaçôes do mundo consegue ver. Deus é a perspectiva da necessidade, ou da máxima causalidade, que observa com perfeição a concatenação de causas e efeitos em toda extensão. É por essa razão que a ideia de Deus, diferentemente das demais ideias, não parte do ser pensante, mas do próprio Deus, posto que, caso o "eu" pudesse criar e vislumbrar tal ideia de perfeição, poderia, até mesmo, conhecer todas as coisas e criar a si mesmo e a tudo, seria onisciente e onipotente. O indivíduo é "substância finita”, e sua perspectiva, pelo contrário, é a da máxima dúvida, do desconhecimento de toda a suposta causalidade do mundo. E a faculdade dos juízos acaba sempre tomando como verdade aquelas percepçôes de mundo que visam, de algum modo, beneficiar o "eu". É por essa razão que, mesmo que o homem não consiga visualizar a perfeita verdade com clareza, uma máxima cartesiana diz que o homem deve abster-se de julgar, toda vez que a verdade de uma coisa não estiver clara (DESCARTES, 2004, p. 129). Os indivíduos não conseguem vislumbrar a totalidade necessária e causal do mundo, não por que ela não existe e o mundo é contingente, mas porque, de acordo com suas respectivas metafísicas, o homem não é capaz de alcançar a absoluta necessidade substancial.

Apesar da alegada causalidade nas metafísicas expostas, e mesmo que não se possa, segundo elas, falar de Deus como a contingência suprema, ponto de vista da absolutez da deidade é o único capaz de visualizar toda a causalidade inerente à natureza. Ato contínuo, é por meio de sua vontade ou, ao menos, de sua força, que se segue uma causalidade, de modo que é Deus aquela substância totalizadora que conecta a cada causa um efeito, e que concatena as causas dessa forma. Nada impede que se diga, destarte, que Ele imputa a cada fato natural uma consequência natural.

Ainda que ambas se identifiquem como "ciência", as ciências naturais e a ciência jurídica têm como objeto, respectivamente, a natureza e as normas jurídicas, que, como defende Hans Kelsen (2009), filósofo do direito austríaco do século XX, se dão a partir de princípios diversos. Causalidade é o princípio que rege as coisas na natureza, de modo que estas estáo em relação de causa e efeito. Segundo a relação de causa e efeito, se algo (A) é, um outro algo (B) se dá; este é efeito daquele. As ciências naturais se preocupam, pois, em investigar as relaçôes de causalidade do mundo, a forma como se relacionam as coisas na natureza, com o intuito de esboçar a totalidade causal das relaçóes naturais. Por outro lado, as normas jurídicas não operam a partir da causalidade, pois não se pode afirmar, a partir de um direito positivo, que se determinada conduta (A) ocorre, determinada consequência (B) se dá, isto é, que da conduta A decorre, 
como um efeito em relação à causa, a consequência jurídica B. Da mesma forma que as ciências naturais têm como objeto a natureza, as ciências jurídicas têm como objeto as normas jurídicas, cuja aplicação depende da vontade de um indivíduo. O que a ciência do direito pode afirmar, portanto, é que se a conduta A ocorre, a sanção B deve ocorrer (KELSEN, 2009, p. 86-91).

Logo, o princípio da imputação, diferentemente do princípio da causalidade, tem seus elementos conectados por uma norma estabelecida pela autoridade jurídica, e esta póe a norma através de um ato de vontade. A imputaçáo tem como pano de fundo, portanto, uma lógica normativa, que consiste na imputação de uma sanção coativa como consequência de uma conduta considerada ilícita para o direito positivo.

A imputação que se exprime no conceito de imputabilidade é a ligação de uma determinada conduta, a saber, de um ilícito, com uma consequência do ilícito. Por isso pode dizer-se: a consequência do ilícito é imputada ao ilícito, mas não é produzida pelo ilícito, como sua causa. É evidente que a ciência jurídica não visa uma explicação causal dos fenômenos jurídicos: ilícito e consequências do ilícito. Nas proposiçóes jurídicas pelas quais ela descreve estes fenômenos ela não aplica o princípio da causalidade mas um princípio que - como mostra esta análise - se pode designar por imputação. (KELSEN, 2009, p. 91)

Não seria o quadro formado a partir da perspectiva onipotente metafísico-religiosa, porém, regido pelo princípio da imputação? E não seria a causalidade mera derivação deste? Se isso puder ser interpretado dessa forma, pode-se afirmar que as coisas na natureza não se dão pela relação de causa e efeito - se A é, então B é-, mas pela relação de imputação - se A é, então B deve ser, conforme prescreve certa norma natural instituída por Deus.

Portanto, também as leis naturais descrevem normas nas quais se exprime a vontade divina, normas que prescrevem à natureza um determinado comportamento. E, por isso, uma teoria metafísica do Direito crê poder encontrar na natureza um Direito natural. (KELSEN, 2009, p. 87)

O Direito natural deriva, então, da mundividência metafísico-religiosa, da perspectiva de um absoluto eterno que controla a trama mundana, que prescreve suas normas. Com o abandono de Deus e sua substituição, no ideário cultural, pelo paradigma da ciência, um Direito natural divino não é mais possível e, se não Deus, quem há de fundamentar a existência do Direito? Se sociedade e natureza desvinculam-se da deidade religiosa enquanto fundamentação de todas as coisas, uma nova narrativa deve dar conta de enredar a trama histórica. Nesse momento de queda da religiosidade, as crenças foram deslocadas para novos ideais, de modo que Deus foi neles secularizado.

\section{DAVID HUME E A IDEIA DE NECESSIDADE}

No tocante à filosofia da natureza, e em paralelo à ideia kelseniana de imputação, a teoria de David Hume, filósofo inglês do século XVIII, traz algumas novas consideraçôes para a epistemologia. A preocupaçáo de David Hume, tanto na primeira parte de seu Tratado da 
Natureza Humana, de 1740 (HUME, 2009, p. 15-306), quanto em Uma Investigação sobre o Entendimento Humano, de 1748 (HUME, 2004, p. 19-222), é de explicar o fenômeno da causalidade. Em vez de partir, porém, de uma substância omnividente objetiva, parte da própria percepção. Para que alguém tenha uma ideia de algo, é necessário, para tanto, que nesse indivíduo seja impressa alguma percepção, que ele tenha uma impressão a partir de suas percepções sensíveis - algo próximo da emergência de ideias para Descartes. Após a experiência perceptiva, o indivíduo pode, a partir de ideias criadas pelo pensamento, especular acerca da causalidade de algo, dos efeitos possíveis para determinada causa.

Após se ter uma experiência, ou um conjunto de experiências envolvendo uma coisa, descobre-se efeitos que se repetiram na coisa e em todas as suas semelhantes. Apesar disso, não é possível falar em conexão necessária entre as coisas experimentadas e suas semelhantes, e nem, em razão disso, na manutenção futura da relação de causalidade da própria coisa com seus efeitos. Não existe nenhuma demonstração que prove que os efeitos da coisa vão continuar acontecendo, pois não há demonstração a priori que relacione a causalidade de uma coisa à causalidade de coisas semelhantes. E como, ainda assim, esta causalidade existe? O que fundamenta a criação das relaçóes de causalidade, se náo é possível concatenar racionalmente eventos semelhantes, eventos que contenham relação de causa e efeito próximas?

O hábito, segundo Hume, é uma conjunção não racional entre causalidades de coisas semelhantes. Sua ocorrência requer a memória de uma experiência anterior conjugada à memória de outra experiência semelhante. "[...] toda crença relativa a fatos ou à existência efetiva de coisas deriva exclusivamente de algum objeto presente à memória ou aos sentidos e de uma conjugaçáo habitual entre esse objeto e algum outro" (HUME, 2004, p. 79). O hábito ocorre não através da razão, mas por meio de um instinto, ou tendência. É este que permite que haja a percepção subjetiva de certas repetiçôes na natureza, que configura a ideia de causalidade própria do hábito. O instinto é uma espécie da ideia de conjunção causal entre coisas, um poder mecânico que age nos indivíduos e que cria essa ideia.

[...] todo efeito tem infinitamente várias causas, e, toda causa, infinitamente vários efeitos. [...] Nenhum processo depende de uma única causa isolada. Partindo dessa perspectiva, esforços foram feitos para que o conceito de causa como tal, enquanto algo inútil, fosse dispensado, e para substituí-lo pelo de "condiçóes" ou "componentes" de eventos, na medida em que a noção de efeito fosse eliminada, em favor da ideia de "aquilo que resulta". Pensou-se, porém, que entre as condiçóes ou componentes de um evento, era necessário designar uma em particular como "decisiva", de modo que [...] uma distinção é feita entre o conceito coletivo de todas as condiçóes de um efeito tomadas juntas, e a causa no sentido mais estreito de "imediata" ou de "mudança decisiva em um dos fatores condicionantes", de forma que o conceito de causa não é realmente dispensado, mas apenas modificado. (KELSEN, 1973, p. 189, tradução nossa)

A conexão necessária de todas as coisas, esse poder imperceptível, mencionado por Descartes e por Spinoza, que rege todas as relaçóes de causa e efeito e que o homem não percebe por limitação de sua capacidade, não passa, para Hume, da crença em uma ideia: a ideia de necessidade. A crença nada mais é que a expectativa de que ocorra determinado efeito. Ela leva 
em conta, a partir do hábito, a maior probabilidade de certas causas aparentes acarretarem determinados efeitos. Apenas o hábito, ou seja, a repetição da causação, produz uma impressão que é capaz de sugerir uma ideia de conexão necessária referente a esta relação de causalidade. A conexão necessária, por fim, é uma ideia causada pela impressão do hábito.

[...] a nossa ideia de necessidade e causação provém inteiramente da uniformidade que se observa nas operaçóes da natureza, nas quais objetos semelhantes estão constantemente conjugados, e a mente é levada pelo hábito a inferir um deles a partir do aparecimento do outro. (HUME, 2004, p. 122)

Caso a teoria de Hume continuasse a sustentar a existência de uma necessidade substancial absoluta da natureza, por mais que abandonasse o personagem de Deus como representante desta necessidade, não abandonaria o ideal ascético (NIETZSCHE, 1998, p. 87-149), o ponto de objetividade que performa toda cena. Contudo, seu iter filosófico consiste transformar esse ponto objetivo em um ponto subjetivo, em assumir o ponto normativo como subjetivo.

Em suma, a necessidade é estruturada pelas ideias de conjunção habituais, e não é possível - ou, ao menos, não é praticável - especular sobre uma necessidade que seja pura causa, isto é, uma necessidade independente do hábito e da percepção. Sendo a causa pura indefinível, seu signo é o acaso (HUNE, 2004, p. 137), pois é ele que expressa a impossibilidade do estabelecimento de uma conexão necessária a priori. A necessidade para Hume, portanto, não é a substância infinita que, aos poucos, é cada vez mais descoberta, mas uma ideia, e uma ideia que, apesar do acaso caótico da situaçáo real, permite a criaçáo de determinadas leis da natureza, ao permitir ao homem delimitar a probabilidade, a partir do hábito, da ocorrência de certos resultados a partir de determinadas condiçóes previamente elencadas. Esta ideia permite, como entende Kelsen (1973), com que o princípio da causalidade seja libertado das amarras necessitaristas, e possa se concentrar em processos de equivalência fenomenologicamente localizados.

Precisamente na analogia do princípio da retribuição, unindo seus dois elementos em uma sequência uniforme, a lei causal é, uma era, originalmente, concebida, e dessa forma entendida como o padrão básico da regularidade natural como tal. Mas esta ideia não poderia mais ser sustentada, uma vez que se tornou necessário abandonar como injustificável a assunção de uma conexão imanente entre causa e efeito, e substituí-la pela ideia de uma dependência meramente funcional. Nesta concepção, a sequência natural de fenômenos não é mais mantida como um elemento essencial. Dependência funcional também pode ser obtida entre ocorrências simultâneas. Mas se ocorrências simultâneas estâo em dependência funcional, elas também são reversíveis. E a ciência moderna é, de fato, capaz de apontar a multitude de conexôes, na qual nenhuma distinção temporal entre antes e depois aparece. (KELSEN, 1973, p. 190, tradução nossa)

Já Kelsen preocupa-se, principalmente em sua Teoria pura do direito (2009), de 1934 (reeditado em 1960), em construir uma ciência do direito totalmente separada da lógica da causalidade. Primeiramente, preocupa-se em afastar o ser do dever-ser, isto é, a natureza das normas sociais. Para que uma compreensão pura do direito positivo possa ocorrer, e esta é a perspectiva da teoria kelseniana, os momentos da criação de uma norma e da existência da norma devem ser radicalmente separados, como que momentos pertencentes a diferentes registros: o do 
ser e o do dever-ser. Existe uma barreira de intransponibilidade entre a norma e a normatização, de modo que a totalidade jurídica nada mais é que uma totalidade de normas. Norma não são apenas as leis, mas também a Constituição, os regimentos, os decretos, e assim por diante, incluindo neste conjunto até mesmo as decisóes judiciais e administrativas do Estado. Para que haja a criação de uma norma - seja pela via legal, seja pela via judicial, seja pela via executiva - o ato de vontade de um agente do Estado deve estar fundado em uma norma jurídica. Só há norma se houver outra norma, anterior (KELSEN, 2009).

No entanto, a fundamentação sucessiva de uma norma em outra norma - que Kelsen chama de "dinâmica jurídica" - é, obviamente, limitada, e logo encontra uma impossibilidade de continuidade. Pois se a Constituição é o último fundamento normativo positivo de um dado ordenamento jurídico, qual seria seu fundamento? Segundo Kelsen, toda Constituição se fundamenta, ainda, na Constituição anterior, e assim sucessivamente, até se atingir a primeira Constituição positiva histórica. Mas esta regra contém uma exceção, segundo a qual uma Constituição não pode se fundamentar na anterior caso aquela tenha sido posta por meio de uma revoluçáo, que o filósofo do direito entende como um golpe de Estado e, portanto, uma modificação ou substituição ilegítima da Constituição. Ocorre que alcançando-se sucessivamente a última Constituição histórica legítima, ainda será necessário fundamentar a legitimidade dela em algo, e é neste momento em que surgem os problemas.

Há várias propostas, de autores diversos, de que se fundamente a Constituiçáo em algum conceito ao menos minimamente indeterminado. Carl Schmitt (1982), por exemplo, a fundamenta em uma unidade política, seja ela o "povo" ou o "monarca”; Jürgen Habermas (2012) fundamenta-a na razão comunicativa, isto é, na participação democrática discursiva; John Rawls (1997), por sua vez, opta por uma justiça liberal. Contudo, há que se observar que as diversas fundamentaçóes jurídicas diferentes do Direito, as diversas maneiras de lhe garantir legitimidade, nada mais fazem que tomar uma certa moral subjetiva por objetiva e, pois, enredam a ciência jurídica em uma narrativa causal.

É por esse motivo que Kelsen é extremamente cauteloso neste ponto. Ao depararse com uma Constituição última que necessita legitimar-se, Kelsen conclui que nada mais é possível deduzir, além do simples fato de que aquele ordenamento, caso ele exista, é, ao menos minimamente, obedecido e que, portanto, é eficaz. A validade de um ordenamento é dedutível de sua eficácia, e esta depende, basicamente, de uma obediência mínima. Caso esta obediência ocorra, nada mais se pode afirmar além do fato de que ela ocorre. Existe, no entanto, alguma norma extrajurídica que impele os sujeitos a obedecerem a este direito positivo (CHAHRUR, 2016). Apesar de esta ser, possivelmente, uma norma de ordem moral, Kelsen propóe que ela seja ficticiamente deslocada para dentro da ciência do direito, não como uma norma posta, é claro, mas como uma norma pressuposta. É esta norma pressuposta que, na teoria kelseniana, fundamenta todo o ordenamento, razão pela qual Kelsen a denomina de "norma fundamental" (KELSEN, 2009, p. 50-51). Com o auxílio da ficção, Kelsen cria um ponto de referência último, 
que torna a imputação possível, sem que este ponto coincida com qualquer ponto da realidade, sem que sua ciência entre em alguma trama causal qualquer.

O número dos elos de uma série imputativa não é, como o número dos elos de uma série causal, ilimitado, mas limitado. Existe um ponto terminal da imputação. Na série causal, porém, tal ponto não existe. A pressuposição de uma primeira causa, de uma prima causa, o análogo do ponto terminal da imputação, é inconciliável com a ideia da causalidade - pelo menos com a ideia da causalidade tal como ela se apresenta nas leis da física clássica. A representaçáo de uma primeira causa que, como vontade criadora de Deus ou como vontade livre do homem, desempenha na metafísica religiosa um papel decisivo, é igualmente um resíduo do pensamento primitivo em que o princípio da causalidade ainda não se havia emancipado do da imputação. (KELSEN, 2009, p. 101-102)

Se é possível afirmar que o princípio da imputação implica na necessidade, isto é, na fixidez, de um ponto normativo último, independente da extensão do quadro normatizado, e que o princípio da causalidade implica na necessidade, isto é, na infinitude, da extensão do quadro causal, independente da fixidez de um ponto causal último, pode-se concluir que as propostas de Hume e de Kelsen não estão nada distantes. Apesar de Kelsen defender que o princípio da imputação deve ser afastado das ciências da natureza (KELSEN, 2009), ele também defende a particularização fenomenológica como ferramenta destas (KELSEN, 1973). E o que seria o princípio da imputação kelseniano senão a proposta de uma particularização fenomenológica de um campo, a saber, do campo normativo? Esta mesma particularização visualiza - ou faz ciência de - "aquilo que resulta" a partir da escolha de certas condiçóes, quais sejam: um direito limitado às normas coativas estatais; um conceito de "normas coativas estatais" que se estende desde as normas particulares até a norma mais universal dentro de um Estado. O resultado, a "ciência pura do direito", é um direito que se fundamenta dinamicamente das normas particulares até a constituição, e cujo fundamento final - ficcionalizado na Norma Fundamental pressuposta - nada mais é que a crença no hábito da observância de determinado direito, hábito calcado na percep̧̧ão.

Sendo assim, pode-se dizer que a proposta de Hume, ao atribuir a alcunha de "acaso" à necessidade absoluta, não afasta o princípio da imputação das ciências naturais, pois permite a dinamicidade do ponto de vista da ciência da natureza, a possibilidade de escolha (ou imputação) de determinadas situações fáticas como condições para a averiguação de determinadas variações delas resultantes, evitando-se, assim, a preocupação de se imputar infinitamente efeitos a causas (posto que é esta preocupação que exige a aposição de uma "causa última” necessária). Tanto nas ciências naturais, quanto nas ciências humanas, e na ciência jurídica em específico, não se trata, como forma de tornar possível uma investigação, de separar o princípio da causalidade e o princípio da imputação, mas de perceber que ambos os princípios são o mesmo fenômeno visto de perspectivas distintas. Enquanto "causalidade", o fenômeno "realidade" tem a estrutura de um mito, posto que sua existência é misticamente entendida como a priori universal, de modo que ocorre uma confusáo entre os pontos de vista subjetivos e um suposto ponto de vista objetivo 
da totalidade. Enquanto "imputação", no entanto, o fenômeno "realidade" tem a estrutura de uma ficção, tendo em vista que sua existência é condicionada à subjetividade do espectador, que escolhe alguns elementos da realidade para construir seu quadro de análise.

A separação anteriormente trazida entre causalidade e imputação não traz, verdadeiramente, uma diferença ontológica, mas uma diferença fenomenológica. Ao passo que da imputaçáo afirma-se que "se ocorre A, deve, de acordo com uma norma objetiva particular subjetivamente posta, ocorrer B", a causalidade altera a sentença, ao afirmar que "se ocorre A, ocorre B, pois ambos estão concatenados de acordo com uma norma objetiva universal". A perspectiva eminentemente causal ignora o fato de que se guia por um cientificismo que desloca a subjetividade de quem vê a realidade para a própria realidade. Ideologia, segundo Slavoj Žižek, não é uma manipulação que ocorre no nível do saber, uma falsificação do conhecimento, mas algo que se dá no próprio agir, um agir que se dá de uma certa forma apesar do saber ${ }^{1}$. Quando alguém, apesar de ter o conhecimento de algo, age como se não o tivesse, isto se dá porque age de acordo com tal ideologia, contrária àquele saber. Este é o problema, na contemporaneidade, tanto da física quântica quanto da democracia: apesar de seus defensores entenderem que ambas são criaçốes humanas, agem como se não o soubessem, como se fossem coisas naturais.

\section{GIORGIO AGAMBEN E O PERFORMATIVO}

Ambos os princípios, da causalidade e da imputação, estão, no entanto, mais próximos do que aparentam, pois derivam de um ancestral comum: a regra da retribuição (KELSEN, 1973; 2009). Esta regra, que rege a vida em comum do homem primitivo, é representada pela retaliação, isto é, consiste na lei de talião. Àquele que causa algum mal deve ser aplicada pena igual ou equivalente, àquele que causa algum bem deve ser aplicado prêmio igual ou equivalente.

Antes de se adentrar nos pormenores acerca desta regra, tomar-se-ão algumas inferências de Hans Kelsen a respeito de uma possível aproximação histórica entre causalidade e imputação. Já na filosofia da natureza dos pré-socráticos é possível antever, segundo Kelsen, algumas características dessa co-originalidade de ambos os princípios. O ponto de partida do jurista austríaco é demonstrar que a concepção de mundo grega desta época "ainda está impregnada com a ideia de valores originados na esfera social” (KELSEN, 1973, p. 167, tradução nossa). Tendo a sociedade grega antiga resolvido seus problemas a partir do lado mítico-religioso, ou

1 Slavoj Žižek aborda esta problemática em algumas passagens de seu livro The sublime object of ideology, de 1989: "[...] Agora nós demos um passo decisivo à frente; estabelecemos um novo modo de ler a fórmula marxiana 'eles não sabe o que fazem, mas o fazem': a ilusão não está do lado do saber, ela está já no lado da realidade em si, do que as pessoas fazem. O que elas não sabem é que sua própria realidade social, sua atividade, é guiada por uma ilusão, por uma inversão fetichista. $\mathrm{O}$ que lhes passa despercebido, o que elas não reconhecem, não é a realidade, mas a ilusão que está estruturando sua realidade, sua atividade social real. Eles sabem muito bem como as coisas realmente são, mas mesmo assim eles agem como se não soubessem. A ilusão é portanto dupla: ela consiste em não perceber a ilusão que está estruturando nossa relação real e efetiva com a realidade. E essa não percepção, ilusão inconsciente, é o que se pode chamar de fantasia ideológica. [...] fantasia é precisamente a maneira como a fissura antagonística é mascarada. Em outras palavras, fantasia é um meio através do qual a ideologia leva em conta, antecipadamente, sua própria falha." (ŽIŽEK, 2008, p. 29-30 e 142, tradução nossa). 
não-científico, que nada tem de interesse em investigar a realidade do mundo, a natureza se torna objeto de um pensar racional, e este se emancipa, pois, do político-social. Dois momentos marcam a constituição científica, que podem ser separados em uma "primeira ciência da natureza" e uma "nova ciência da natureza".

Para esta primeira ciência da natureza, como já antes para a visão primitiva da natureza, a comunidade autoritária, o estado, providencia o primeiro esquema para a ordem que se tenta ler no cosmos: pois é precisamente o estado que é habitualmente aceito como ordem per se, e em virtude de uma especulação teológica muito mais antiga, é comumente considerado um valor absoluto. Mas a noção de uma lei para o mundo, i. e., natureza, que inicialmente nada mais é que a projeção do estado no cosmos, manifestamente se separa de seu arquétipo para ter um significado totalmente diferente. [...] A nova ciência da natureza começa apenas no ponto em que o mito sai de cena; mas isso tem início com

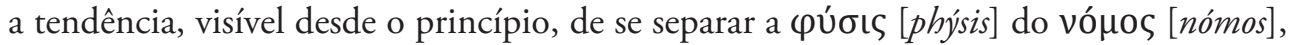
a natureza da sociedade, e de se criar uma oposição entre ambas, e consequentemente entre ciência e política, ou, ao menos, de se estabelecer um dualismo das duas, que era ainda totalmente estranho à mente primitiva. (KELSEN, 1973, p. 167-168, tradução nossa)

Os filósofos pré-socráticos, nesse ínterim, buscam um fundamento final a partir do

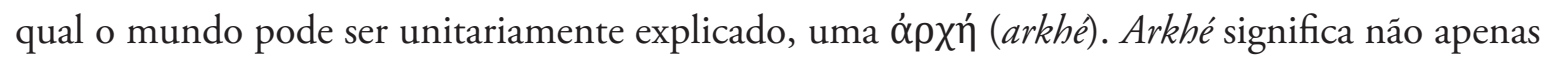
"origem", ou "início", mas também "regra" ou "força", de modo que essa regra única, investigada pelos pré-socráticos, que estaria na origem de todas as coisas, essa "mon-arquía”, é um princípio de mobilidade, responsável por toda movimentação mundana. É por isso que, mesmo que, por exemplo, Tales e Anaxímenes tenham proposto como causa primeira, respectivamente, a água e o ar, ambas essas arkhés são entendidas animicamente, ou seja, como possuidoras de alma e, portanto, de razão, pois não são apenas substância amorfa, mas causa motriz que ordena e controla.

Este primeiro aspecto do princípio da causa primeira não refletiria uma das características da regra da retaliação? Da mesma forma que, a partir da regra da retribuição, uma norma impôe uma punição a um ato ilícito culposo, a partir da ideia de uma causa fundamental, a arkhé conecta um efeito a uma causa, acrescentando-os a uma cadeia causal. Essa característica da regra de retribuição é chamada de princípio da bipartição, posto que determina a redução do âmbito retributivo a apenas dois elementos: uma conduta prejudicial e a sua punição: "Esta ideia da natureza da causação é, em geral, uma forte reminiscência da visão primitiva da natureza da retribuição; da causa decorre o efeito, assim como a culpa, ou, mais precisamente, o indivíduo que pratica uma ação vil, incorre em uma punição" (KELSEN, 1973, p. 169, tradução nossa).

A bipartição polariza o mundo em ilícito e consequência, ou, na ciência, em causa e efeito, que, no limite, implica na polarização entre natureza e causa primeira. O mesmo pode ser dito do princípio da imputação que, em seu limite, polariza o seu campo de atuação em conduta humana e norma final.

Há, contudo, um outro aspecto da causa primeira que deve ser observado, e que reflete outra característica da regra da retribuição. Segundo a regra da retribuição, punição e a conduta 
ilícita são dois momentos que devem equivaler para que possam se estabelecer uma relação, para que tenham correspondência. No mesmo sentido, na formação de suas ciências naturais, os pré-socráticos atribuem grande importância ao fato de que os elementos da natureza sejam equivalentes, para que possam, também, corresponder, para que a ideia de que as causas ensejam efeitos náo impeça a natureza de ser vista como um todo harmônico de mútua equivalência.

A condição para que haja a referida equivalência entre os elementos é que surjam do mesmo lugar, que advenham, pois, da mesma causa motriz. Se assim for, todas as coisas da natureza dela derivam e, em razão disso, todas as coisas configuram a própria substância natural da causa primeira, e estão, portanto, em permanente harmonia, são qualitativamente semelhantes. Isso não quer dizer, é claro, que as coisas não se diferenciem quantitativamente, de modo que as relaçóes de causa e efeito se dáo, assim como as relaçôes entre culpa e consequência, entre quantidades equivalentes. Essa ideia de harmonia está presente no postulado da conservação de energia na ciência contemporânea, de forma que o princípio da causalidade, em razão deste postulado, foi ressignificado, na contemporaneidade, a partir da equivalência de energias. A esta característica proveniente da regra da retribuição dá-se o nome de princípio da equivalência.

Apenas através de uma mudança de sentido mais radical, poderia o princípio da causalidade se transformar no (ou, mais precisamente, levar ao surgimento do) princípio da equivalência de energias. Enquanto componente da teoria causal - agora eliminada da física moderna, ou substituída pelo princípio da equivalência - [o princípio da equivalência] origina-se na doutrina da retribuição, a saber, em seu princípio básico de que semelhante será pago com semelhante. (KELSEN, 1973, p. 187, tradução nossa)

Ocorre que, em razão da duplicaçáo constitutiva da regra da retribuiçáo em phýsis e nómos, ambos os princípios dela derivados, da causalidade e da imputação, são concomitantemente atravessados um pelo outro (KELSEN, 2009). Ao passo que a ciência sustenta o princípio da causalidade como princípio que engendra a análise da natureza, o princípio da imputação opera como seu anverso obsceno. Portanto, ao olhar para os pré-socráticos e para a modernidade a partir de uma perspectiva progressista, tentando afastar causalidade e imputaçáo por meio de uma teoria puramente jurídica, Kelsen não percebe que a imbricação de ambos os princípios se reproduz durante a história, não sendo superada por um pretenso progresso científico moderno.

Se, todo conhecimento de mundo se estrutura na lei da retaliação - lei da igualdade e do mandamento que fundamenta todo Direito - o conhecimento da natureza se baseia em uma certa ontologia jurídica, de modo que se torna não apenas conhecimento de algo já dado, mas criação de mundo. Isso quer dizer que uma certa ontologia jurídica permeia performativamente as concepções ocidentais de mundo.

Existe algo a mais na natureza retributiva do direito, na sua imputabilidade, que torna qualquer narrativa possível. O direito origina-se do juramento, da lógica da promessa jurada, promessa esta que gera uma dívida que se extingue com o cumprimento, e cujo descumprimento acarreta a culpa e constitui o devedor inadimplente, passível de punição e, logo de retaliação. Mas o que torna possível um juramento, isto é, como um juramento pode, automaticamente, 
pelo simples ato de se jurar, constituir uma dívida? Como uma promessa qualquer gera, ao mesmo tempo, uma obrigação, que pode ser cobrada com o não cumprimento daquela? $\mathrm{O}$ juramento se estrutura em um tipo de enunciado específico, que a filosofia da linguagem chama de performativo. O enunciado performativo não é, como a denotaçáo comum, um enunciado que descreve determinado estado de coisas da realidade, mas um enunciado que produz um fato a partir da enunciação. Ele remete a um estado originário da linguagem, em que não há uma clara distinção entre sentido e denotação, em que a significação das coisas se confunde com as coisas significadas.

Como funciona realmente o performativo? O que permite que um determinado sintagma adquira, através da sua simples pronúncia, a eficácia do ato, desmentindo a antiga máxima que sustenta que as palavras e as coisas estão separadas por um abismo? Nesse caso, é certamente essencial o caráter autorreferencial da expressão performativa. Tal autorreferencialidade não se esgota simplesmente no fato de o performativo - conforme observa Benveniste (ibid., p 274) - tomar a si mesmo como referente, na medida em que remete a uma realidade que ele próprio constitui. O que importa salientar é que a autorreferencialidade do performativo sempre se constitui através de uma suspensão do caráter denotativo normal da linguagem. (AGAMBEN, 2011, p. 65)

O caráter performativo que a lógica jurídica originária do juramento-promessa-dívida estende a toda tentativa de conhecimento de mundo, inclusive à própria antropogênese. A delimitaçáo biológica de um ponto de passagem do símio ao homem na chamada "teoria da evolução", consistindo ou de alguns critérios fisiológicos ou do próprio fato da linguagem - isto é, de ser o homem aquele único animal que se constitui como ser na linguagem -, nada mais é que a inscrição performativa desse ponto na linguagem, a decisão do ser falante de que ele se diferencia dos demais animais: "[...] único entre os seres vivos, o homem não se limitou a adquirir a linguagem como uma capacidade entre outras de que é dotado, mas fez dela a sua potência específica, ou seja, na linguagem ele pôs em jogo a sua própria natureza" (AGAMBEN, 2011, p. 79).

Resultante da racionalidade protojurídica do performativo, a ideia de progresso das ciências, que condiciona a tentativa kelseniana de separar causalidade e imputação, condensa todo o problema do "pôr em jogo a própria natureza" na contemporaneidade. Nesse movimento, é a própria noção de progresso que é sub-repticiamente naturalizada e que rege as diferentes formulaçôes científicas. Os ideais de bem-estar e de futuro são atribuídos ao progresso científico, pervertendo seu sentido, e desconsiderando-se totalmente o anverso obsceno do pretenso progresso da humanidade.

No entanto, as consequências da progressão da humanidade são catastróficas. Por um lado, a progressão geométrica do número de pessoas na Terra implica na necessidade de uma ocupação de terras cada vez maior, de modo que uma luta por mais e mais cercamentos de terras tem lugar (SCHMITT, 2014). Disso decorre a marginalização de pessoas, e a consequente ocupação, por estas, de novas terras, e assim sucessivamente, até não haver mais terras desocupadas. Essa condição dá lugar a uma crescente demanda por terra, que implica na submissão de pessoas sem 
terra a donos de terra, e em uma crescente reproduçáo social da desigualdade. Aos deslocamentos e cercamentos físicos corresponde a tendente periferização do trabalhador em relação aos meios de produção, isto é, sua crescente dispensabilidade no processo de produção.

Se progresso científico significa facilitação das técnicas e das tecnologias de criação, significa, também, a diminuição da participação humana nos processos de criação. Do aumento quantitativo e qualitativo das máquinas no modo capitalista de produção, por exemplo, decorre a redução da mão de obra no processo de produção de mercadorias e, consequentemente, desemprego e despossessão de terras; estas são ocupadas mais e mais por máquinas. E o aumento dos desempregados, afastados não só da condição de trabalhador, mas cada vez mais, também da condição de consumidor, provoca a queda da taxa de lucro, e a necessidade de cada vez mais maquinização, um ciclo infinito de geração de miséria (MARX, 2017).

E se estes marginalizados inevitavelmente tornam-se criminosos ou indigentes e, em razão disso, sofrem as penas do direito, é evidente que a lógica retributiva não deixou de imperar, também, no direito penal contemporâneo, mas foi simplesmente transmutada. Como no capitalismo o tempo de trabalho livre se torna o principal elemento para a produção de mercadorias (MARX, 2013), ou seja, o lucro está intimamente relaciona ao tempo de trabalho, o direito penal passa a obedecer a esta mesma lógica, de modo que a pena, determinada normativamente a partir de variados critérios e de uma ampla gama de opçóes, é valorativamente equivalente ao ilícito cometido, seguindo estritamente a lógica da retaliação. Contudo, o ideal progressista, proveniente da retribuição, reflete-se nesta última: as doutrinas do direito penal contemporâneo se negam a aceitar essa bruta equivalência entre ilícito e pena, e os pensadores do direito penal progressista, esquivando-se da lex talionis, defendem, como fins jurídicos deste, os ideais da proteção da sociedade ou da ressocialização do criminoso (PACHUKANIS, 2017).

A ideia progressista performativamente suspende os problemas do mundo, e, em seu lugar, justapóe uma nova ideia "natural" otimista de que a progressão temporal é sempre benéfica. Por esse motivo, os mitos contemporâneos que de algum modo suavizam a forma de compreender o mundo devem ser contornados, de modo que elenquemos ideias que tenham por base os fundamentos materiais das relações simbólicas. É a partir dessas refutações que uma ontologia filosófica que leve em consideração a ficção e o acaso, e que não se sujeite à regra da retribuição, pode ser pensada.

\section{CONSIDERAÇÓES FINAIS}

A mudança de perspetiva operada por Hume, da ontologia à epistemologia, torna possível a visualização de tudo o que se tem de natural como um processo de criação de verdade. No mesmo sentido, a correlação sugerida por Kelsen entre causalidade e imputação permite concluir que há uma simbiose do jurídico e do metafísico no ato de criação desse processo de verdade. $\mathrm{E}$ isso possibilita ver o problema propriamente ontológico, o problema do ser, de um outro ponto 
de vista, um ponto de vista que coaduna com a ideia de suspensão performativa de um estado de coisas como forma de criação de um novo estado de coisas. Nos parágrafos seguintes, faz-se um breve resumo do exposto.

No primeiro capítulo, os princípios da imputação e da causalidade, trazidos por Kelsen, foram abordados e diferenciados, sendo que o princípio da causalidade diz respeito a uma relaçáo natural de causa e efeito, e o princípio da imputação diz respeito a uma relação normativa de ilícito e punição. Da causalidade deduz-se que de algo (causa) decorre alguma coisa (efeito); da imputação deduz-se que de algo (ilícito) deve ocorrer alguma coisa (punição). Vários exemplos metafísicos do início da modernidade foram trazidos, com o escopo de mostrar a imbricação dos princípios da causalidade e do princípio da imputação. Apesar de a metafísica de Descartes, por exemplo, buscar explicar a relação de causalidade na natureza, o filósofo francês, paradigma da filosofia moderna, coloca Deus como uma causa final, causa esta que, ao dizer como as coisas se dão, imputa efeitos a causas, criando uma teia causal com um ponto final.

No segundo capítulo, a teoria de Hume acerca do entendimento e a teoria de Kelsen acerca da ciência jurídica são expostas, com o intuito de desmistificar a trama necessitarista das ciências emergentes. Hume propóe que toda necessidade absoluta, ou causa final, não passa de uma ideia, de algo criado pelo entendimento humano a partir das experiências, uma crença que se dá a partir da percepção do homem de algumas repetições habituais no mundo. No limite, não se pode falar de uma causa final necessária, mas táo somente de puro acaso, do desconhecido. Kelsen, seguindo esta teorização, propóe criar uma teoria do direito completamente separada das demais, uma teoria fechada nas normas, de modo a não correr o risco de cair em uma causa final para o direito (que não passaria de um "direito natural”). Dessas duas formulações, é possível concluir que, diferentemente do que Kelsen almeja, não há que se falar em separar o princípio da causalidade do princípio da imputação, posto que ambos são os dois lados da mesma moeda, e não passam de diferentes formas de posicionar um ponto de vista frente a realidade.

No terceiro capítulo, um excurso histórico se deu, com o intuito de mostrar a genealogia de ambos os princípios, que remetem à primitiva "regra da retribuição". A longínqua ciência da Grécia Antiga, iniciada pelos chamados filósofos pré-socráticos, teve como fundamento de criação uma regra muito presente nos laços sociais, a regra da retribuição, popularmente conhecida por "lei de talião", de modo que os principais elementos dessa lei constituíram as teorizaçôes sobre as coisas do mundo, desde a antiguidade até a modernidade. E o princípio retributivo só pode ter lugar em razão de uma especificidade linguística, em razão da possibilidade de endividamento e promissão próprias do caráter performativo da língua, como explica Giorgio Agamben.

Se os problemas envolvendo uma possível relação entre a metafísica e o direito puderam ser em alguma medida delineados, o próximo passo seria questionar de modo mais preciso este caráter performativo da constituição da dívida. Se a regra retributiva é determinante para a existência do jurídico, e se o performativo está conectado com uma espécie de ontologia do dever-ser, o humano estaria fadado a constituir suas formas de vida a partir da retribuição? Este 
é um questionamento que demanda outras reflexóes, mas entendemos ser um ponto de partida para se pensar uma reinvenção ontológica da filosofia.

\section{REFERÊNCIAS}

AGAMBEN, Giorgio. O Sacramento da linguagem: Arqueologia do juramento (Homo sacer II, 3). Tradução de Selvino José Assmann. 1. ed. Belo Horizonte: UFMG, 2011.

CHAHRUR, Alan Ibn. A importância teórica e prática da norma fundamental. Revista de informação legislativa: RIL, v. 53, n. 211, p. 35-53, jul./set. 2016. Disponível em: <http:// www12.senado.leg.br/ril/edicoes/53/211/ril_v53_n211_p35>. Acesso em: 05 de out de 2019.

DAWSON, Christopher. Progresso e religiāo: uma investigação histórica. 1. ed. Tradução de Fabio Faria. São Paulo: É Realizaçóes, 2012.

DESCARTES, René. Meditaçôes da filosofia primeira. 1. ed. Edição bilíngue. Tradução de Fausto Castilho. Campinas: Editora Unicamp, 2004.

HABERMAS, Jürgen. Direito e democracia: entre facticidade e validade. 2. ed. Tradução de Flávio Beno Siebeneichler. Rio de Janeiro: Tempo Brasileiro, 2012.

HUME, David. Uma investigação sobre o entendimento humano. In: HUME, David. Investigaçôes sobre o entendimento humano e sobre os princípios da moral. 1. ed. Tradução de José Oscar Almeida Marques. São Paulo: Editora UNESP, 2004. p. 19-222.

HUME, David. Livro I - Do entendimento. In: HUME, David. Tratado da natureza humana: uma tentativa de introduzir o método experimental de raciocínio nos assuntos morais. 2. ed. Tradução de Déborah Danowski. São Paulo: Editora UNESP, 2009. p. 15-306.

KELSEN, Hans. The emergence of the causal law from the principle of retribution. In: KELSEN, Hans. Essays in legal and moral philosophy. 1. ed. Tradução de Peter Heath. Dorcrecht, Holanda: D. Reidel Publishing Company, 1973.

KELSEN, Hans. Teoria pura do direito. 8. ed. Tradução de João Baptista Machado. São Paulo: Editora WMF Martins Fontes, 2009.

MARX, Karl. O Capital: crítica da economia política. 1. 1. Tradução de Rubens Enderle. 1. ed. São Paulo: Boitempo, 2013.

MARX, Karl. O Capital: crítica da economia política. 1. 3. Tradução de Rubens Enderle. 1. ed. São Paulo: Boitempo, 2017.

NIETZSCHE, Friedrich W. Genealogia da moral: uma polêmica. Tradução, notas e posfácio de Paulo César de Souza. 1. ed. São Paulo: Companhia das Letras, 1998. 
PACHUKANIS, Evguiéni. Teoria geral do direito e marxismo. Tradução de Paula Vaz de Almeida. 1. ed. São Paulo: Boitempo, 2017.

RAWLS, John. Uma teoria da justiça. Tradução de Almiro Pisetta e Lenita M. R. Esteves. 1. ed. São Paulo: Martins Fontes, 1997.

SCHMITT, Carl. Teoría de la constitución. 1. ed. Tradução de Francisco Ayala. Madrid: Alianza Editorial, 1982.

SCHMITT, Carl. O nomos da Terra no direito das gentes do jus publicum europæum. 1. ed. Tradução de Alexandre Franco de Sá, Bernardo Ferreira, José Maria Arruda e Pedro Hermílio Villas Boas Castelo Branco. Rio de Janeiro: Contraponto; Ed. PUC-Rio, 2014.

ŽIŽEK, Slavoj. The sublime object of ideology. 2. ed. Londres: Verso, 2008. 